\title{
A Comparison between Radio Meteor and Airglow Winds
}

\author{
G. HeRnANDEZ* and R.G. Roper** \\ *Aeronomy Laboratory, National Oceanic and Atmospheric Admin., \\ Boulder, Colorado, U.S.A. \\ **School of Aerospace Engineering Georgia Institute of Technology, \\ Atlanta, Georgia, U.S.A.
}

(Accepted June 10, 1978)

\begin{abstract}
A comparison between the winds near 97 kilometers altitude has been made from observations of the 17924K (5577 ̊) OI line emission at Fritz Peak Observatory $(39.8 \mathrm{~N}, 195.5 \mathrm{~W})$ and with a meteor radar facility at Atlanta $(34 \mathrm{~N}, 84 \mathrm{~W})$, from August 1974 to November 1975. Since the optical emission measurements are made only at night, the nighttime meteor radar measurements have been used, weighted by an airglow emission rate profile. The results show general agreement in both the zonal and meridional wind vectors, but with the variations in the amplitude of the meridional winds at the northernmost station (Fritz Peak Observatory) larger than those at Atlanta, a result of the smoothing inherent in producing the meteor winds.
\end{abstract}

\section{Introduction}

In the past, several attempts have been made to compare winds measured over the height range 80 to $100 \mathrm{~km}$ by the radio meteor technique with winds measured by other methods. Correlations between meteor winds and those determined by means of ground triangulation of chemical releases from rockets (see, for example, ReEs et al., 1972; Lloyd et al., 1972) have been singularly unsuccessful. Comparisons between meteor winds and partial reflection winds (a gated pulse radio technique which utilizes the backscatter signals from ambient electrons), on the other hand, have been excellent, "provided similar data reduction techniques are applied to each data set" (Stubbs, 1973; Stubbs and Vincent, 1973). In this paper, a comparison is made between winds measured by the radio meteor technique, and those inferred from groundbased observations of the optical doppler shifts of the naturally occurring emissions in that region of the atmosphere. Although the radio and optical techniques have been in existence for about 25 and 10 years respectively, to our knowledge no comparison of the winds measured by the two techniques has previously been made.

\section{The Method}

In order to make a meaningful comparison of the two types of measurements it is necessary to minimize the inherent differences between the two wind measuring techniques. These basic differences are: a) the meteor radar echo winds can be 
resolved in altitude, while the optical measurements are associated with an emission height profile, $b$ ) the meteor radar winds are measured around the clock, while the lower thermosphere optical measurements are made only at night, and c) the optical measurements require at most $15 \mathrm{~min}$ per measurements, while the Atlanta radio meteor winds typically require a few days of measurement. Instantaneous line of sight drifts are available from each individual meteor echo; however, the all sky Atlanta radio meteor facility suffers from a reduced echo rate due to reflections from aircraft (see ROPER, 1975) - in order to produce a significant ensemble average from which to determine the wind vector for each hour, several days of data are processed using the method of Groves (1959). The high powered meteor radar operated by the University of Illinois (GELLER et al., 1977) is able to produce significant wind components on a $15 \mathrm{~min}$ timescale. This facility has also been in operation since 1974 , but has a limited operating schedule. To date, insufficient simultaneously

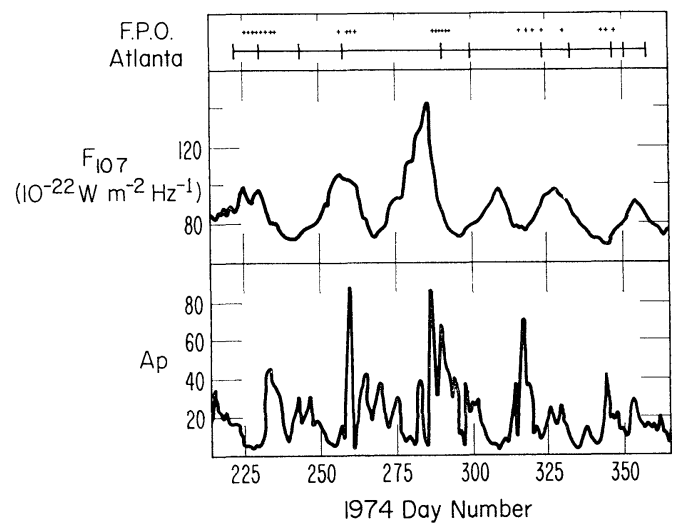

Fig. 1. Dates of measurement of lower thermosphere winds at Fritz Peak Observatory and Atlanta durnig 1974. Solar and geomagnetic activities are shown for reference.

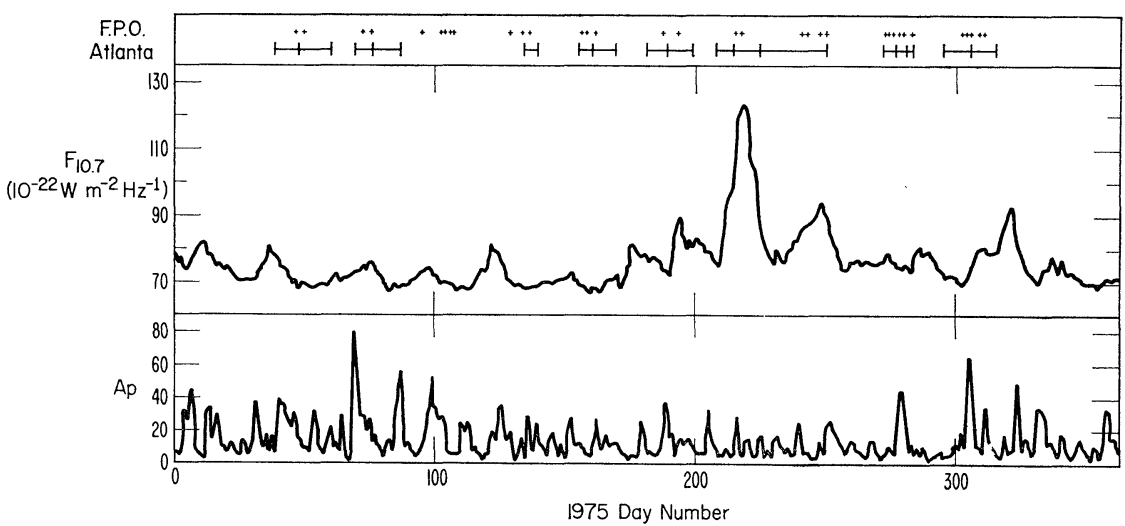

Fig. 2. Dates of measurement of lower thermosphere winds at Fritz Peak Observatory and Atlanta during 1975. Solar and geomagnetic activities are shown for reference. 
measured data is available from this source for meaningful comparison with the airglow results.

The differences in the data sets compared here have been reduced by weighting the meteor radar winds with an airglow profile for a latitude similar to that of the two stations, namely the profile of O'BRIEN et al. (1965) measured at Wallops Island $\left(38^{\circ} \mathrm{N}\right)$. The use of a fixed altitude profile is supported by the findings of Donahue et al. (1973) and the inferences of HERNANDEZ (1976) of an emission profile of effectively fixed altitude. The difference in time coverage of the two measurements has
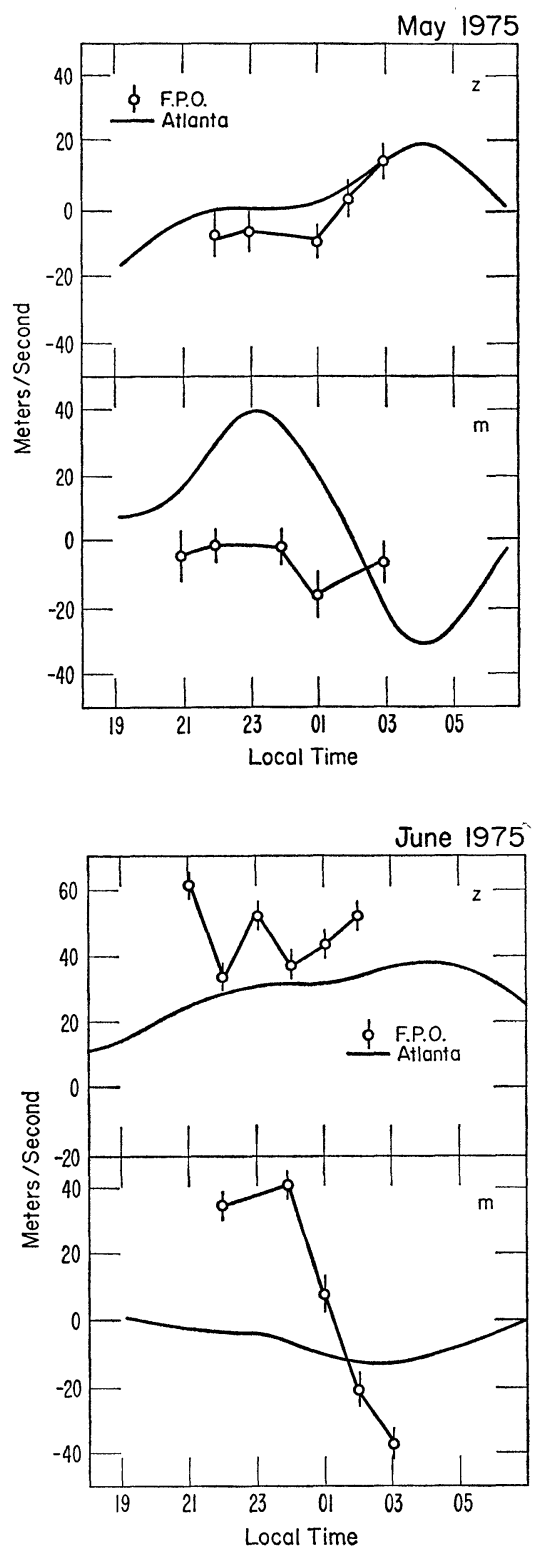

Fig. 3. Comparison of the winds measured at the two stations as a function of local time, during May 1975. The meteor radar winds have been weighted by an airglow profile.

Fig. 4. Comparison of the winds measured at the two stations as a function of local time, during June 1975. The meteor radar winds have been weighted by an airglow profile. 
been allowed for by comparing the data only for overlapping times, while the inherent smoothing in the meteor winds is partially compensated by averaging the optical data for the days of measurement into $1 \mathrm{hr}$ groups (noting that, as a rule, the optical
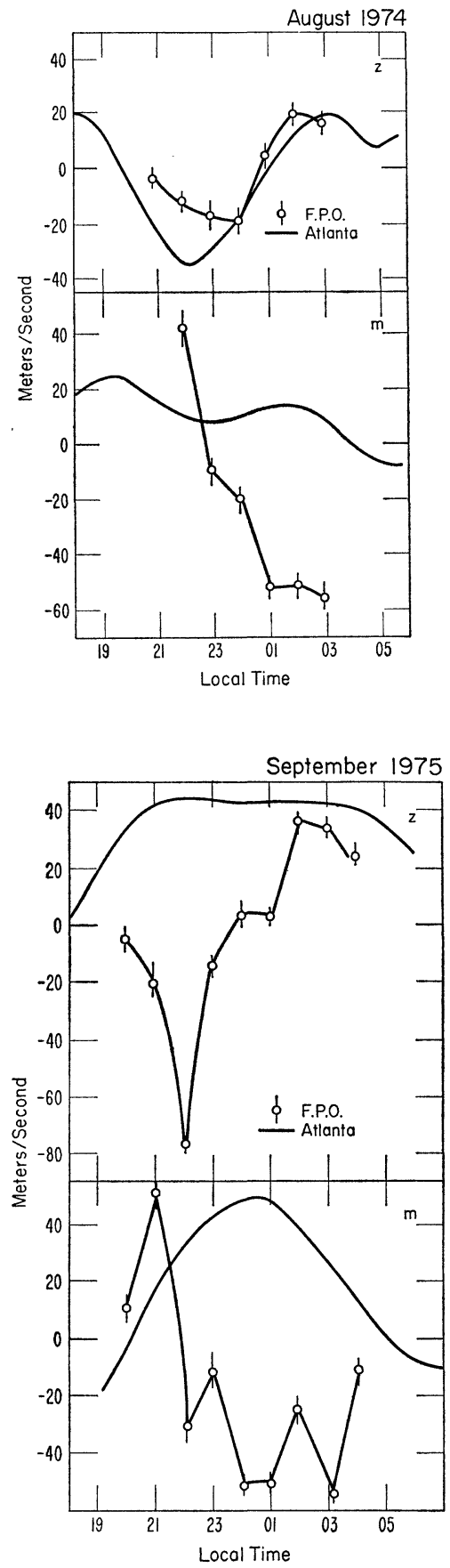

Fig. 5. Comparison of the winds measured at the two stations as a function of local time, during August 1974. The meteor radar winds have been weighted by an airglow profile.

Fig. 6. Comparison of the winds measured at the two stations as a function of local time, during September 1975. The meteor radar winds have been weighted by an airglow profile. 
data does not encompass a measuring period as long as that used to deduce the radio meteor winds). For obvious reasons, only the nighttime meteor results are used.

The meteor radar winds from Atlanta, Georgia $(34 \mathrm{~N}, 84 \mathrm{~W})$ and the optical winds from Fritz Peak, Colorado (39.9N, 105.5W) from August 1974 to November 1975 have been used in the comparison, with the meteor radar winds treated as described in the previous paragraph to minimize the differences between the two set of measurements.

Figures 1 and 2 show the dates of measurement at the two stations, as well as the solar and magnetic conditions during the times of the observations. As shown
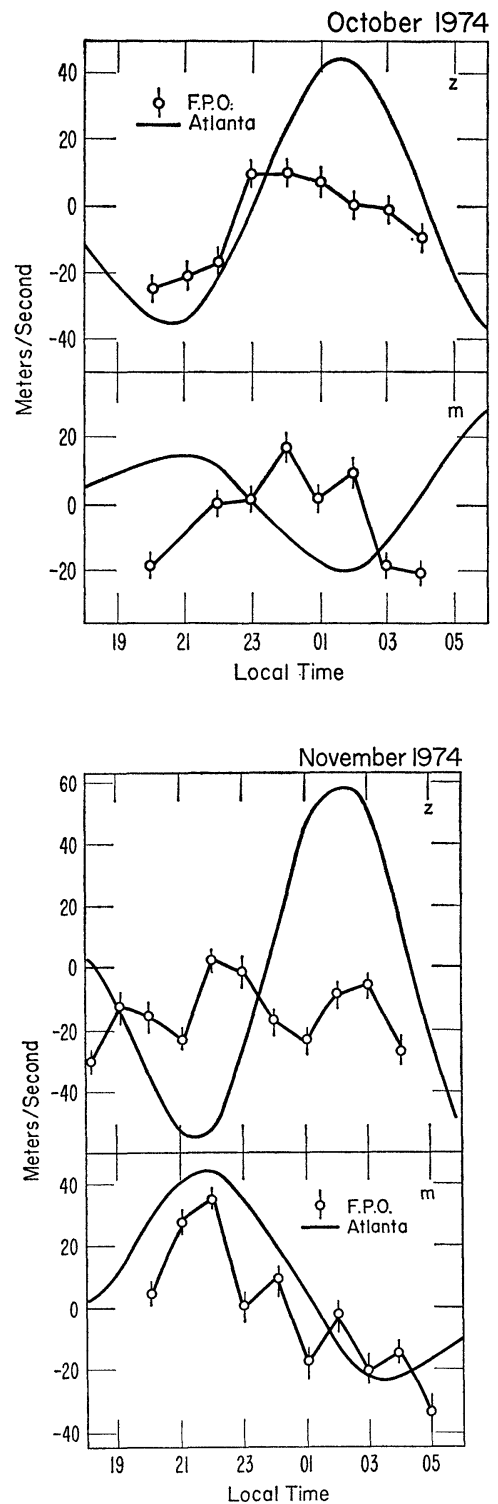

Fig. 7. Comparison of the winds measured at the two stations as a function of local time, during October 1974. The meteor radar winds have been weighted by an airglow profile.
Fig. 8. Comparison of the winds measured at the two stations as a function of local time, during November 1974. The meteor radar winds have been weighted by an airglow profile. 
in the figures, for both 1974 and 1975, the majority of the measurements are for quiet (solar minimum) conditions, except for some storminess about day 250 in both years.

Figures 3 to 8 show some typical wind comparisons where more often than not the shapes and magnitudes of the zonal winds are similar, while the meridional winds show larger excursions for the F.P.O. than for the Atlanta data, as well as somewhat different phase. The convention of positive winds southward and eastward is followed in the figures.

The data from these figures, as well as that from other periods not shown here have been made more tractable by extracting the one-half of the maximum excursion of the data (for overlapping times) for both stations, as well as noting the time of the maximum (or maxima) excursion, and these statistics are shown in Figs. 9 to 12. In general this "amplitude" of the wind at Fritz Peak is larger than that of Atlanta by about 10 to $15 \mathrm{~m} / \mathrm{s}$, with the exception of the zonal wind of late 1974 . However, the late 1974 epoch was quite unusual in that the "mean" zonal winds for both stations were easterly, while normally the mean wind is found to be westerly, as it is for most of 1975. The phase relationships show the southernmost station (Atlanta)
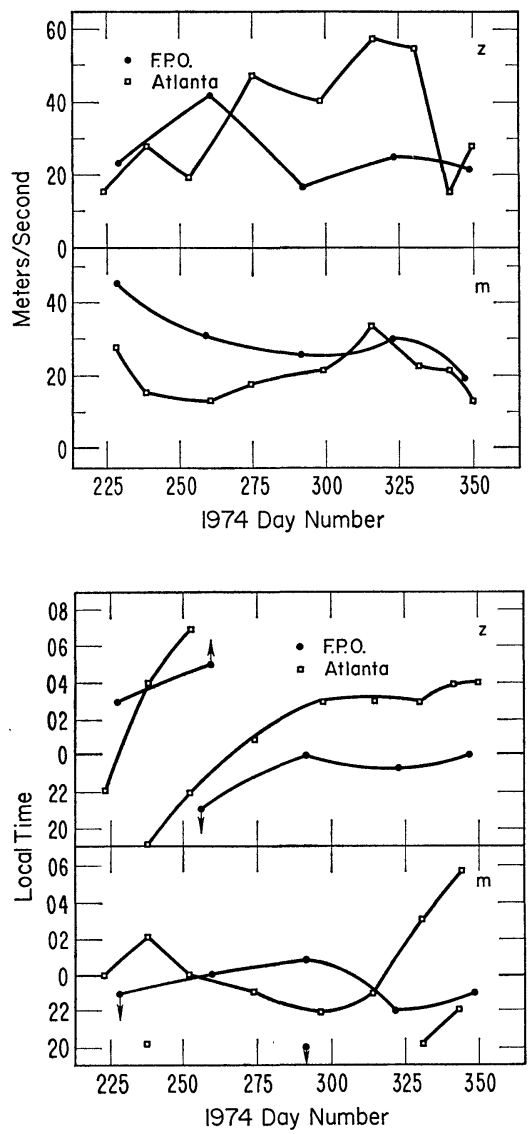

Fig. 9. 'Amplitude' of the winds during 1974 for both stations (See text).
Fig. 10. Phase of the winds for the two stations during 1974 (See text). 


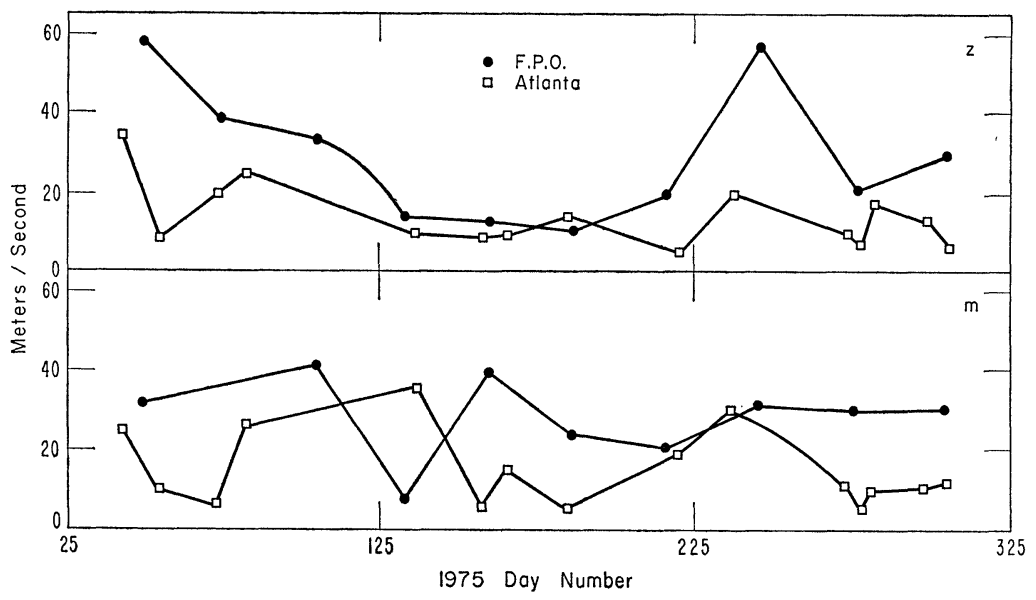

Fig. 11. 'Amplitude' of the winds during 1975 for both stations.

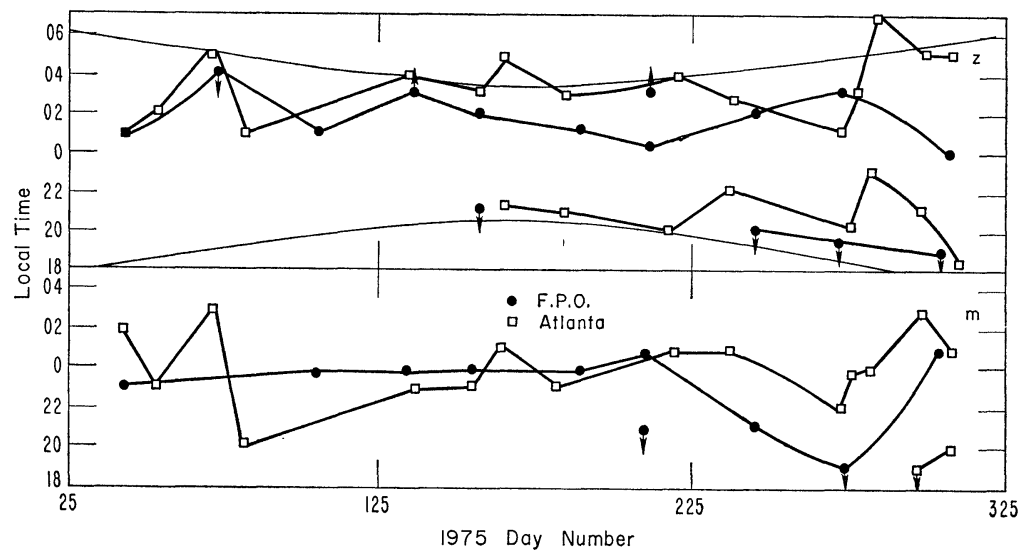

Fig. 12. Phase of the winds for the two stations during 1975. The light lines in the upper panel show the times of $12^{\circ}$ solar depression at Fritz Peak, which delineate the times of useful optical measurements.

having a maximum later than that observed at Fritz Peak in the zonal component, while for the meridional component Fritz Peak lags in the summer and leads in the winter. The zonal phase difference of about $2 \mathrm{hr}$ (in local time) is about the time difference expected for the longitude difference of the two stations-as if both stations are looking at a "standing wave" phenomenon, or looking at an event of much larger scale than the separation between the two stations. It is interesting to note that after both solar storms during the autumn of 1974 and 1975 the amplitudes of the excursions increased while the phases seem to advance and recede for the zonal and meridional components respectively. However, since the storms occurred at about the same date each year, it is not possible to say whether or not the observed changes are exclusively caused by the storms, or they may be part of the normal seasonal behavior. 
Other similarities found for both stations are the roughly $6 \mathrm{hr}$ separation in maxima observed in the zonal winds and partially in the meridional winds for a given station.

This work has been supported in part by the Atmospheric Research Section of the National Science Foundation under Grant No. ATM75-14414, and the National Aeronautics and Space Administration under Grant No. NGL 11-002-004.

\section{REFERENCES}

Donahue, T.M., B. Guenther, and R.J. Thomas, Distribution of atomic oxygen in the upper atmosphere deduced from OGO-6 airglow observations, J. Geophys. Res., 78, 6662-6689, 1973.

Geller, M.A., S.A. Bowhill, and G.C. Hess, A description of the University of Illinois meteor radar system, and some first results, J. Atmos. Terr. Phys. 39, 15-24, 1977.

Groves, G.V., A theory for determining upper atmosphere winds from radio observations on meteor trails, J. Atmos. Terr. Phys., 16, 344-356, 1959.

HERNANDEZ, G., Lower-thermosphere temperatures determined from the line profiles of the OI 17924K

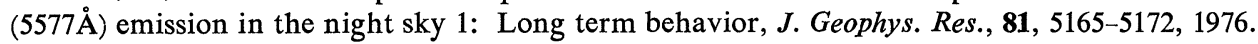

Lloyd, K.H., C.H. Low, B.J. MCAvANEY, D. Rees, and R.G. Roper, Thermospheric observations combining chemical seeding and ground based techniques-1. Winds, turbulence and the parameters of the neutral atmosphere, Planet. Space Sci., 20, 761-789, 1972.

O'Brien, B.J., F.R. Allum, and H.C. Goldwire, Rocket measurement of midlatitude airglow and particle precipitation, J. Geophys. Res., 70, 161-175, 1965.

ReEs, D., R.G. ROPER, K.H. LlOYD, and C.H. Low, Determination of the structure of the atmosphere between 90 and $250 \mathrm{~km}$ by means of contaminant releases at Woomera, May 1968, Phil. Trans. Roy. Soc. London, 271A, 631-663, 1972.

Roper, R.G., The measurement of meteor winds over Atlanta, Radio Sci., 10, 363-369, 1975.

StubBs, T.J., The measurement of winds in the D region of the ionosphere by the use of partially reflected radio waves, J. Atmos. Terr. Phys., 35, 909-919, 1973.

Stubbs, T.J. and R.A. Vincent, Studies of D region drifts during the winters of 1970-1972, Aust. J. Phys., 26, 645-660, 1973. 